\title{
Adaptive call admission control and resource allocation in multi server wireless/cellular network
}

\author{
Madhu Jain ${ }^{1} \cdot$ Ragini Mittal ${ }^{2}$
}

Received: 7 February 2014/ Accepted: 6 October 2015/Published online: 3 November 2015

(C) The Author(s) 2015. This article is published with open access at Springerlink.com

\begin{abstract}
The ever increasing demand of the subscribers has put pressure on the capacity of wireless networks around the world. To utilize the scare resources, in the present paper we propose an optimal allocation scheme for an integrated wireless/cellular model with handoff priority and handoff guarantee services. The suggested algorithm optimally allocates the resources in each cell and dynamically adjust threshold to control the admission. To give the priority to handoff calls over the new calls, the provision of guard channels and subrating scheme is taken into consideration. The handoff voice call may balk and renege from the system while waiting in the buffer. An iterative algorithm is implemented to generate the arrival rate of the handoff calls in each cell. Various performance indices are established in term of steady state probabilities. The sensitivity analysis has also been carried out to examine the tractability of algorithms and to explore the effects of system descriptors on the performance indices.
\end{abstract}

Keywords Cellular network - Admission control · Handoff priority $\cdot$ Handoff guarantee $\cdot$ Guard channel Subrating $\cdot$ Balking $\cdot$ Reneging $\cdot$ Blocking

Ragini Mittal

m234ragini@gmail.com

Madhu Jain

madhufma@iitr.ernet.in; drmadhujain@yahoo.co.in

1 Department of Mathematics, IIT Roorkee, Roorkee 247667, India

2 Department of Mathematics, St. John's College, Agra 282002, India

\section{Introduction}

With the advancement of technology, the cellular mobile user population has been growing at a rapid pace. New generation wireless/cellular networks are designed to support adaptive multimedia service by controlling individual ongoing flow of calls. The admission control is employed to decide how a connection or call should be admitted into the network. A new connection or call is said to be blocked if its requests for resources cannot be met by the network. Call blocking probability is an important quality of service (QoS) parameter in cellular networks. One of the key QoS issues in wireless/cellular network is how to control the handoff dropping. Handoff is the situation in which a call in one cell attempts to migrate into a neighboring cell and if the level of resources required by the call cannot be satisfied by the new (neighboring) cell, the handoff is denied and call is dropped. In real time networks, the dropping of a call in progress is considered to have more negative impact from users' perspective than the blocking of a newly requested call. Thus, the optimal strategies for prioritizing handoff calls verses new calls are to be needed to maintain the bandwidth (resource) reserves for the future handoff. Jain and Rakhee (2003) developed an integrated traffic model using guard channel scheme in which priority is given to handoff calls over the new calls. The problem of resource reservation and admission control was studied by Rashad and Kantardzic (2006) for wireless mobile network. Jain et al. (2008) developed a handoff priority-based channel allocation scheme for the cellular radio network based on the channel sub-rating with balking, reneging and buffer. A handoff scheme with wireless access points (WAP) was proposed by Shet et al. (2010). This scheme uses WAP as the ad-hoc routing station, to connect to the base stations. Jain and Mittal (2011) analyzed the 
performance of a double layer cellular network using new call bounding scheme and directed retry scheme. A study on minimization of handoff failure in $2 \mathrm{G} / 3 \mathrm{G}$ cellular network was presented by Kumar et al. (2012). Jain et al. (2014a, b) proposed a call admission control and resource allocation of OFDM wireless networks with buffer and subrating. Again, Jain and Mittal (2015) suggested a call admission control for soft handoff coverage in CDMA cellular system with balking and reneging.

In wireless/cellular networks, to ensure that ongoing calls are not dropped while the owner mobile stations room among cells, the handoff calls should be admitted with guarantee. Moreover, some calls such as emergency rescue or business transactions cannot be dropped before service completion. These applications will require the handoff guaranteed service. For guaranteed and handover routing in low earth orbit constellation, Galtier (2001) suggested the geographical reservation scheme. Huang et al. (2004) proposed a traffic model consisting of three service classes: handoff priority, handoff guarantee and best effort. To reduce the blocking probability of handoff voice calls in progress, a few researchers have proposed a subrating scheme. According to this scheme the reserve channels are splitted into two half rate channels to serve more than one call. Jain and Rakhee (2001) suggested the subrating channel assignment for PCS networks for integrated voice/data cellular traffic model. Jain (2003) and Jain et al. $(2003 \mathrm{a}, \mathrm{b})$ proposed prioritized handover scheme with subrating. Again, Jain (2005) developed a queuing model with cutoff priority scheme, in which the subrating of guard channels was provided to serve more handover voice calls. Islam and Murshed (2007) investigated an advance resource reservation and call admission control scheme for cellular networks to achieve efficient results in case of network congestion. Wu et al. (2009) developed analytic models based on 1-D Markov process in microcell and 2-D Markov process in macrocell, in which a call admission control scheme based on the channel sub-rating is used. A mathematical model to estimate the dropping probabilities of cellular wireless networks by queuing handoff instead of reserving guard channels was proposed by Samanta et al. (2010). Hashemin and Fatemi Ghomi (2012) developed a mathematical model for the resource allocation in stochastic networks using multi-objective decision making algorithm. A heuristic method for consumable resource allocation in multi-class dynamic PERT networks was considered by Yaghoubi et al. (2013). Jain et al. (2015) presented an ANN model for multi channel infinite buffer queue under N-policy.

Buffering of the calls is one of the methods to reduce the blocking of the incoming calls. In the buffering process if the arriving call finds all the channels in the target cell occupied, it may be queued and if any channel is released it is assigned to the next call waiting in the queue (buffer). Lin (2003) has studied a dynamic resource allocation policy for GPRS with buffering mechanisms. Balking and reneging are two important aspects of customer's behaviors. When an incoming call finds all the channels busy with other calls, then the call may not join the queue (buffer); this state is considered as balking. In case of reneging, after joining the queue for some time, the call leaves the system due to impatience or some other reasons. Haghighi and Mishev (2006) discussed a general parallel finite buffer multiserver priority queuing system with balking and reneging. A channel allocation scheme was suggested by Tang and $\mathrm{Li}$ (2007) to evaluate the performance of the mobile cellular network in which a victim buffer is employed to non-real time calls. The impact of customer's balking and impatience behavior was examined by Artalejo and Pla (2009) on Markovian multiserver model for telecommunication system. Sharma and Purohit (2011) proposed two queueing models (1) priority handoff queueing model with reserve channels and (2) handoff queueing model with channel subrating for wireless cellular network. Jain et al. (2013) and Jain et al. (2014a, b) suggested handoff prioritized call admission control schemes for the cellular radio system having integrated traffic with impatience behavior. An $M^{x} / G / 1$ retrial queueing system with $k$-phases of heterogeneous service under different vacation policies and impatient calls was proposed by Mittal and Jain (2015).

Now-a-days, there is a speedy growth of mobile users. As the available frequency spectrum is limited, it must be efficiently utilized. The main issue in the cellular networks is to decide the number of frequency channels that should be assigned to each cell so that a pre-defined level of grade of service (GoS) can be achieved. Jain et al. (2003a, b) suggested the channel allocation scheme for cellular network to optimally allocate the channel to each cell. Choi et al. (2006) developed a QoS aware selective feedback model and a method for optimal resource allocation. A dynamic channel allocation scheme with efficient channel reservation for handoff calls was proposed by Krishna and Iyengar (2008). Chowdhury et al. (2009) suggested a channel allocation algorithm that assigns optimally minimum channels in a distributed manner. A noble integerprogramming problem was formulated by Wu et al. (2011) to optimize the channel allocation and power control for incoming calls. An optimal channel assignment scheme with the objective of maximizing bandwidth with fairness consideration to equalize the bandwidth assignment of flows was investigated by Jayarin and Ravi (2012). Kia et al. (2013) presented a multi-objective mixed-integer nonlinear programming mathematical model to design a group layout of a cellular manufacturing system in a dynamic environment. For multi rate wireless networks, 
optimization models and optimization algorithms were suggested by Ning et al. (2015).

In this investigation, we develop a cellular traffic model with integrated traffic and handoff guaranteed service. To give the priority to handoff calls over the new calls, guard channel scheme is used along with sub-rating scheme and buffer. The iterative algorithm is used to generate the arrival rate of handoff calls. The optimal allocation algorithm is suggested to allocate the optimal number of guard channels and ordinary channel in each cell of cellular cluster having $\mathrm{K}$ cells. The rest of the paper is organized as follows. Section 2 deals with traffic model along with the assumptions and notations. Various performance indices are established in Sect. 3. Optimal allocation algorithm and iterative algorithm are given in Sect. 4. Sensitivity analysis is carried out in Sect. 5. Finally, conclusion is drawn in Sect. 6.

\section{The traffic model}

To develop the traffic model, we consider a wireless/cellular network, consisting of a cluster of $K$ hexagonal microcells of uniform size. The $j$ th cell has $c_{j}(j=1,2, \ldots, K)$ channels to serve the incoming calls which are classified into four types (1) new voice calls (2) new data calls (3) handoff voice calls, and (4) handoff data calls. The network provides two types of services, the handoff guaranteed service and handoff prioritized service. However, it is assumed that the handoff guaranteed service can traverse ' $L$ ' cells at most. The handoff prioritized service is provided at low price in comparison to handoff guaranteed service. In handoff guaranteed service, the handoff dropping is not allowed whereas a low handoff dropping can be tolerated in case of handoff prioritized scheme. To give the priority to handoff calls, $r_{j}$ channels out of $c_{j}$ channels in each cell are reserved and are allowed to be occupied by handoff attempts only. The rest of channels, i.e., $s_{j}=c_{j}-r_{j}$ serve all types of calls including handoff guaranteed calls while providing the service the handoff guaranteed calls are preference in the cells (see Fig. 1). The subrating of reserve channels is considered in order to accommodate more handoff voice calls. To reduce the blocking of handoff voice calls, there is provision of a finite buffer wherein handoff voice calls can wait. The handoff voice calls may balk or renege from the system. All the calls arrive in Poisson fashion and the call holding time and cell residence times are assumed to be exponentially distributed. As the arrival rate of new and handoff calls is interdependent, we suggest an iterative algorithm to generate the arrival rate of the handoff calls. The number of channels to be allocated in each cell of a cluster which minimize the overall blocking probability of calls, we suggest an optimal channel allocation algorithm which helps to assign optimal number of unreserved channels or ordinary channels $\left(s_{j}\right)$ and guard channel $\left(r_{j}\right)$ to each cell in the cluster.

The following notations are used for formulating the traffic model:

TC Number of channels allocated to the cluster

$N \quad$ Buffer size for handoff voice calls

$1 / \mu \quad$ Mean call holding time

$1 / \eta \quad$ Mean cell residence time of each port

$N \quad$ Reneging rate

$B \quad$ Joining probability of handoff voice calls

$\lambda_{j, n v} \quad$ Arrival rates for new voice (new data) calls in

$\left(\lambda_{j, n d}\right) \quad$ the $j$ th cell $(j=1,2, \ldots, K)$

$\lambda_{j, h v}$

$\left(\lambda_{j, h d}\right)$

$\Lambda_{j, n}$

Arrival rates for handoff voice (handoff data)

calls in the $j$ th cell $(j=1,2, \ldots, K)$

Arrival rate of new calls in the $j$ th cell $(j=1$,

$2, \ldots, K)$ cell such that $\Lambda_{j, n}=\lambda_{j, n v}+\lambda_{j, n d}$

$\Lambda_{j, h} \quad$ Arrival rate of handoff calls in the $j$ th cell

$(j=1,2, \ldots, K)$ cell such that

$\Lambda_{j, h}=\lambda_{j, h v}+\lambda_{j, h d}$

$\Lambda_{j} \quad$ Integrated arrival rate of calls in the $j$ th cell

$(j=1,2, \ldots, K) ; \Lambda_{j}=\Lambda_{j, n}+\Lambda_{j, h}$

$P_{j, i} \quad$ Steady state probability that there are $i$ calls in the $j$ th cell $(j=1,2, \ldots, K)$

$B_{j, n} \quad$ Blocking probability of new calls in the $j$ th cell $(j=1,2, \ldots, K)$

$B_{j, h d} \quad$ Blocking probability of handoff data calls in the $j$ th cell $(j=1,2, \ldots, K)$

$B_{j, h v} \quad$ Blocking probability of handoff voice calls in the $j$ th cell $(j=1,2, \ldots, K)$

$B_{j, h} \quad$ Blocking probability of handoff calls in the $j$ th cell $(j=1,2, \ldots, K)$

$D_{j, G} \quad$ Dropping probability of handoff guaranteed calls in the $j$ th cell $(j=1,2, \ldots, K)$

$B_{j} \quad$ Overall blocking probability of calls in the $j$ th cell $(j=1,2, \ldots, K)$

It is to be noted that we consider the performance model of an individual cell so that for the sake of simplicity, we
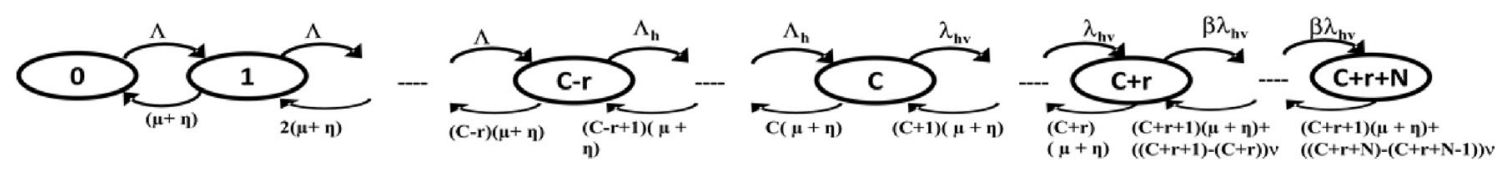

Fig. 1 State transition diagram 
have dropped the suffix $j$. In addition, denote $s=c-r$ (Fig. 1).

The state dependent arrival and service rate are given as

$\Lambda_{i}= \begin{cases}\Lambda, & 0 \leq i \leq s \\ \Lambda_{h}, & s+1 \leq i<c \\ \lambda_{h v}, & c \leq i<c+r \\ \beta \lambda_{h v}, & c+r \leq i \leq c+r+N\end{cases}$

and

$\mu_{i}= \begin{cases}i(\mu+\eta), & 1 \leq i \leq c+r-1 \\ (c+r)(\mu+\eta)+(i-(c+r)) v, & c+r \leq i \leq c+r+N\end{cases}$

The steady state probabilities for the suggested model are obtained using product type results (c.f. Gross and Harris 2003). Thus,

$P_{i}= \begin{cases}\frac{\Lambda^{i}}{i !(\mu+\eta)^{i}} P_{0}, & 0 \leq i \leq s \\ \frac{\Lambda^{s} \Lambda_{h}^{i-s}}{i !(\mu+\eta)^{i}} P_{0}, & s+1 \leq i \leq c \\ \frac{\Lambda^{s} \Lambda_{h}^{r} \lambda_{h v}^{i-c}}{i !(\mu+\eta)^{i}} P_{0}, & c+1 \leq i \leq c+r \\ \frac{\Lambda^{s} \Lambda_{h}^{r} \lambda_{h v}^{r}\left(\beta \lambda_{h v}\right)^{i-(c+r)}}{(c+r) !(\mu+\eta)^{c+r} \prod_{j=1}^{i-(c+r)}[(c+r)(\mu+\eta)+j v]} P_{0}, & c+r+1 \leq i \leq c+r+N\end{cases}$
- The blocking probability of handoff data and handoff voice calls is obtained as

$$
B_{h d}=\sum_{i=c+1}^{c+r+N} P_{i} \quad \text { and } \quad B_{h v}=P_{c+r+N}
$$

- The blocking probability of handoff calls is

$$
B_{h}=\frac{\lambda_{h d} B_{h d}+\lambda_{h v} B_{h v}}{\Lambda_{h}}
$$

- The dropping probability of handoff guaranteed calls is given by

$$
D_{G}=1-\left(1-B_{n}\right)^{L}
$$

- The overall blocking probability and carried load (CL), respectively, are given by where $P_{0}$ can be calculated using the normalizing condition

$$
\sum_{i=0}^{c+r+N} P_{i}=1
$$

\section{Performance measures}

Using steady state probabilities, we can establish various performance indices as follows:

- The blocking probability of new calls is given by

$$
B_{n}=\sum_{i=s+1}^{c+r+N} P_{i}
$$

$$
\begin{aligned}
B & =\frac{\Lambda_{n} B_{n}+\lambda_{h d} B_{h d}+\lambda_{h d} B_{h v}+\Lambda_{h} D_{G}}{\Lambda} \\
\mathrm{CL} & =\frac{\Lambda_{n}\left(1-B_{n}\right)+\lambda_{h d}\left(1-B_{h d}\right)+\lambda_{h v}\left(1-B_{h v}\right)+\Lambda_{h}\left(1-D_{G}\right)}{\Lambda}
\end{aligned}
$$

- The expected number of busy channels is

$$
E[l]=\sum_{0 \leq i \leq c+r+N} i P_{i}
$$

- The number of sub-rated channels is

$E\left[l_{s}\right]=\sum_{c \leq i \leq c+r} 2(i-c) P_{i}$

- The degradation of voice quality is given as 


$$
E[D]=E\left[l_{s} / l\right]=\sum_{c \leq i \leq c+r} \frac{2(i-c) P_{i}}{i}
$$

- The average queue length of handoff voice calls is given by

$$
Q_{h v}=\sum_{c+r \leq i \leq c+r+N}(i-(c+r)) P_{i}
$$

- Using Little's formula the average waiting time of handoff voice is obtained by

$$
W_{h v}=Q_{h v}\left[\left(1-B_{h v}\right) \lambda_{h v}\right]^{-1}
$$

\section{Adaptive algorithms}

In this section, we propose two algorithms: (1) algorithm to assign optimal number of unreserved $\left(s_{j}\right)$ channels and guard channels $\left(r_{j}\right)$ to each cell in the cluster of $\mathrm{K}$ cells and (2) algorithm to compute the arrival rate of handoff calls in each cell.

\section{Allocation of channels}

We assume that there are total TC interference-free frequency channels available in the cellular cluster. The objective is to determine the optimal number of channels $\left(s_{j}^{*}, r_{j}^{*}\right)$ in each of the cells of the cluster, which not only minimizes the overall blocking probability $\left(B_{h}\right)$ of handoff calls in the cluster, but also ensures sufficient level of GoS for new calls. The problem is formulated as a nonlinear integer-programming problem (NIPP) as follows:

\section{Problem}

Minimize $B_{h}=\sum_{j=1}^{K} \frac{\lambda_{j, h v}}{\Gamma} B_{j, h v}\left(s_{j}, r_{j}\right)+\sum_{j=1}^{K} \frac{\lambda_{j, h d}}{\Gamma} B_{j, h d}\left(s_{j}, r_{j}\right)$

subject to $B_{j, n}\left(s_{j}, r_{j}\right) \leq B_{\text {target }}, \quad j=1,2, \ldots, K$

$\sum_{j=1}^{K}\left(s_{j}+r_{j}\right) \leq \mathrm{TC}$

$s_{j}, r_{j} \geq 0, s_{j}, r_{j}(j=1,2, \ldots, K)$ being integers.

Here $B_{\text {target }}$ is the minimum level of GoS to be satisfied by both types of calls. In addition $\Gamma=\sum_{j=1}^{K} \Lambda_{j, h}$. To solve this NIPP we suggest the following optimization algorithm:

\section{Optimization Algorithm}

For each cell $j$ in the cluster, follow the following steps:

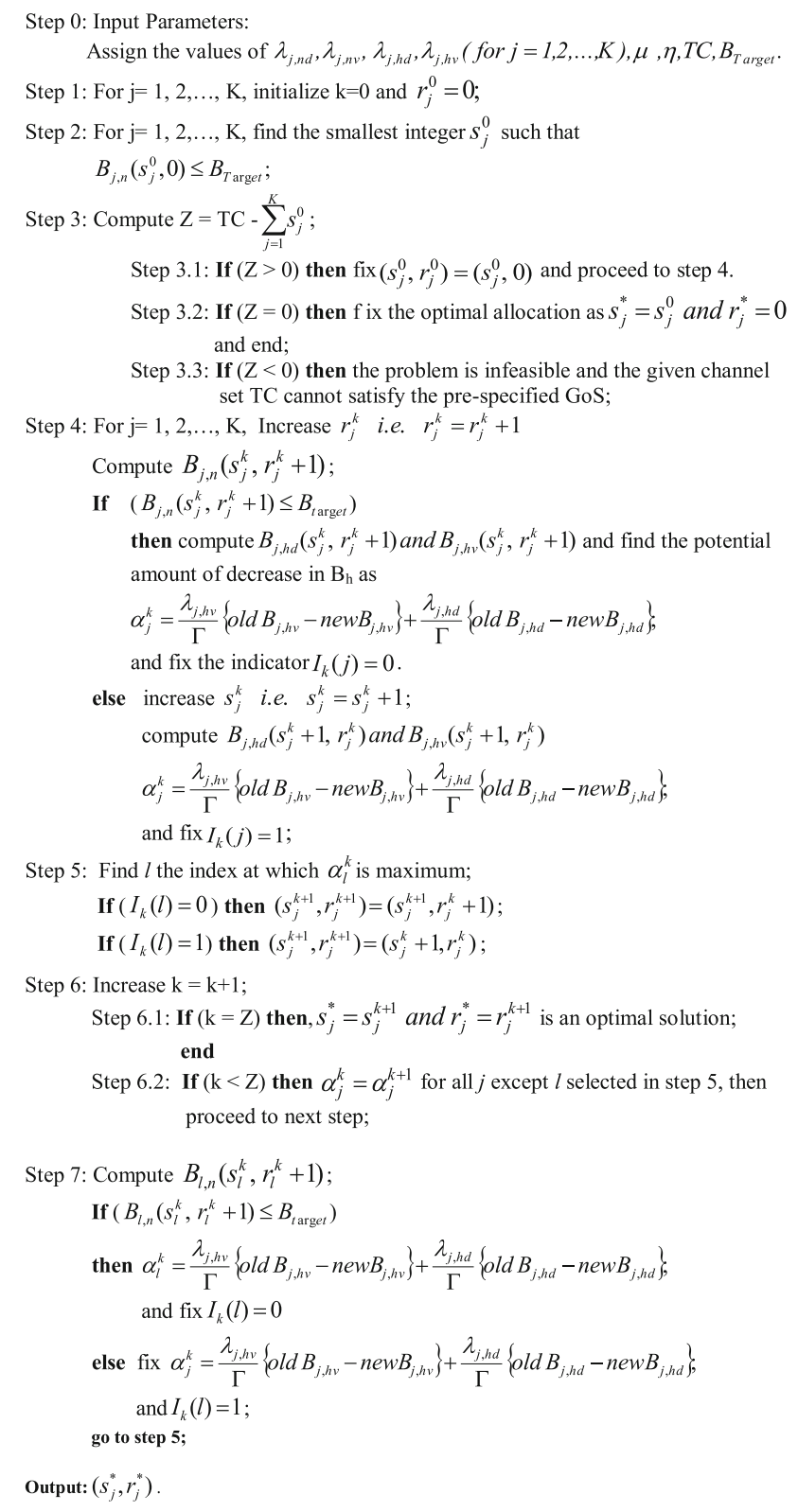

\section{Computation of handoff traffic}

We use the following iterative algorithm to compute the arrival rates of handoff voice and handoff data attempts in each cell. The blocking/dropping probabilities and arrival rates of new attempts and the handoff arrival rates are interdependent and are given by the following relation (see Lin et al. 1996): 
Table 1 Optimal channel allocation taking $B_{\text {target }}=1 \%$

\begin{tabular}{|c|c|c|c|c|c|c|c|c|}
\hline $\mathrm{TC}$ & $\left(s^{*}, r^{*}\right)$ & $B_{n}$ & $B_{h d}$ & $B_{h v}$ & $B_{h}$ & $B$ & $D_{G}$ & CL \\
\hline \multirow[t]{7}{*}{150} & $(13,1)$ & 0.009861 & 0.000823 & 4.97E-06 & 0.00017 & 0.008323 & 0.057728 & 0.991677 \\
\hline & $(16,1)$ & 0.008749 & 0.00078 & 5.38E-06 & 0.000156 & 0.007358 & 0.051359 & 0.992642 \\
\hline & $(18,0)$ & 0.009209 & 0.009209 & 8.67E-04 & 0.002451 & 0.00811 & 0.053997 & 0.99189 \\
\hline & $(21,1)$ & 0.009536 & 0.000946 & $8.10 \mathrm{E}-06$ & 0.000183 & 0.008002 & 0.055872 & 0.991998 \\
\hline & $(23,0)$ & 0.00939 & 0.00939 & $9.36 \mathrm{E}-04$ & 0.002492 & 0.008257 & 0.055034 & 0.991743 \\
\hline & $(26,1)$ & 0.009769 & 0.001032 & $1.00 \mathrm{E}-05$ & 0.000196 & 0.008189 & 0.057203 & 0.991811 \\
\hline & $(28,0)$ & 0.009283 & 0.009283 & $9.57 \mathrm{E}-04$ & 0.002461 & 0.008156 & 0.054419 & 0.991844 \\
\hline \multirow[t]{7}{*}{160} & $(13,1)$ & 0.009861 & 8.23E-04 & $4.97 \mathrm{E}-06$ & $1.70 \mathrm{E}-04$ & 0.008323 & 0.057728 & 0.991677 \\
\hline & $(16,1)$ & 0.008749 & $7.80 \mathrm{E}-04$ & $5.38 \mathrm{E}-06$ & $1.56 \mathrm{E}-04$ & 0.007358 & 0.051359 & 0.992642 \\
\hline & $(19,1)$ & 0.007604 & 7.01E-04 & $5.19 \mathrm{E}-06$ & $1.37 \mathrm{E}-04$ & 0.00639 & 0.044763 & 0.993611 \\
\hline & $(21,2)$ & 0.009749 & $1.10 \mathrm{E}-04$ & 7.37E-08 & $2.06 \mathrm{E}-05$ & 0.008153 & 0.057084 & 0.991847 \\
\hline & $(24,2)$ & 0.008438 & $9.81 \mathrm{E}-05$ & $7.04 \mathrm{E}-08$ & $1.81 \mathrm{E}-05$ & 0.007055 & 0.049573 & 0.992945 \\
\hline & $(26,2)$ & 0.009994 & $1.28 \mathrm{E}-04$ & $1.08 \mathrm{E}-07$ & 2.34E-05 & 0.008349 & 0.058488 & 0.991651 \\
\hline & $(29,2)$ & 0.008702 & $1.13 \mathrm{E}-04$ & $9.83 \mathrm{E}-08$ & $2.05 \mathrm{E}-05$ & 0.007268 & 0.051088 & 0.992732 \\
\hline \multirow[t]{7}{*}{170} & $(14,2)$ & 0.006265 & $4.42 \mathrm{E}-05$ & $1.32 \mathrm{E}-08$ & 8.90E-06 & 0.005272 & 0.037005 & 0.994728 \\
\hline & $(16,3)$ & 0.008952 & $8.08 \mathrm{E}-06$ & $2.14 \mathrm{E}-10$ & $1.57 \mathrm{E}-06$ & 0.007503 & 0.052524 & 0.992497 \\
\hline & $(19,3)$ & 0.007782 & $7.86 \mathrm{E}-06$ & $2.63 \mathrm{E}-10$ & $1.49 \mathrm{E}-06$ & 0.006517 & 0.045793 & 0.993483 \\
\hline & $(21,3)$ & 0.009774 & $1.23 \mathrm{E}-05$ & $5.81 \mathrm{E}-10$ & $2.30 \mathrm{E}-06$ & 0.008171 & 0.057227 & 0.991829 \\
\hline & $(24,3)$ & 0.00846 & $1.12 \mathrm{E}-05$ & $5.94 \mathrm{E}-10$ & $2.06 \mathrm{E}-06$ & 0.00707 & 0.049699 & 0.99293 \\
\hline & $(27,2)$ & 0.007423 & $8.90 \mathrm{E}-05$ & $6.81 \mathrm{E}-08$ & $1.63 \mathrm{E}-05$ & 0.006201 & 0.04372 & 0.993799 \\
\hline & $(29,3)$ & 0.008726 & $1.37 \mathrm{E}-05$ & $9.75 \mathrm{E}-10$ & $2.48 \mathrm{E}-06$ & 0.007286 & 0.05123 & 0.992714 \\
\hline \multirow[t]{7}{*}{180} & $(14,1)$ & 0.006277 & $3.17 \mathrm{E}-07$ & $1.98 \mathrm{E}-13$ & $6.38 \mathrm{E}-08$ & 0.005281 & 0.037075 & 0.994719 \\
\hline & $(16,4)$ & 0.008954 & $7.65 \mathrm{E}-07$ & $1.05 \mathrm{E}-12$ & $1.49 \mathrm{E}-07$ & 0.007504 & 0.052535 & 0.992496 \\
\hline & $(19,4)$ & 0.007784 & $7.82 \mathrm{E}-07$ & $1.49 \mathrm{E}-12$ & $1.48 \mathrm{E}-07$ & 0.006518 & 0.045804 & 0.993482 \\
\hline & $(21,4)$ & 0.009776 & $1.33 \mathrm{E}-06$ & $4.00 \mathrm{E}-12$ & $2.48 \mathrm{E}-07$ & 0.008173 & 0.057243 & 0.991827 \\
\hline & $(24,4)$ & 0.008463 & $1.24 \mathrm{E}-06$ & 4.44E-12 & $2.28 \mathrm{E}-07$ & 0.007072 & 0.049713 & 0.992928 \\
\hline & $(27,4)$ & 0.007445 & $1.17 \mathrm{E}-06$ & $4.92 \mathrm{E}-12$ & $2.13 \mathrm{E}-07$ & 0.006216 & 0.043847 & 0.993784 \\
\hline & $(29,5)$ & 0.008730 & $1.85 \mathrm{E}-07$ & $7.02 \mathrm{E}-14$ & $3.35 \mathrm{E}-08$ & 0.007288 & 0.051249 & 0.992712 \\
\hline
\end{tabular}

Table 2 Optimal channel allocation for TC $=200$

\begin{tabular}{|c|c|c|c|c|c|c|c|c|}
\hline & $\left(s^{*}, r^{*}\right)$ & $B_{n}$ & $B_{h d}$ & $B_{h v}$ & $B_{h}$ & $B$ & $D_{G}$ & $\mathrm{CL}$ \\
\hline \multirow[t]{7}{*}{$B_{\text {target }}=0.01$} & $(14,6)$ & 0.006277 & $1.85 \mathrm{E}-09$ & $1.55 \mathrm{E}-18$ & $3.73 \mathrm{E}-10$ & 0.005281 & 0.037075 & 0.994719 \\
\hline & $(16,7)$ & 0.008954 & 4.97E-10 & $5.23 \mathrm{E}-20$ & $9.65 \mathrm{E}-11$ & 0.007504 & 0.052537 & 0.992496 \\
\hline & $(19,7)$ & 0.007784 & $6.06 \mathrm{E}-10$ & $1.27 \mathrm{E}-19$ & $1.15 \mathrm{E}-10$ & 0.006518 & 0.045805 & 0.993482 \\
\hline & $(21,7)$ & 0.009777 & 1.34E-09 & $6.29 \mathrm{E}-19$ & $2.49 \mathrm{E}-10$ & 0.008173 & 0.057245 & 0.991827 \\
\hline & $(24,7)$ & 0.008463 & $1.36 \mathrm{E}-09$ & $9.47 \mathrm{E}-19$ & $2.51 \mathrm{E}-10$ & 0.007072 & 0.049715 & 0.992928 \\
\hline & $(27,7)$ & 0.007445 & $1.41 \mathrm{E}-09$ & $1.38 \mathrm{E}-18$ & $2.56 \mathrm{E}-10$ & 0.006217 & 0.043849 & 0.993783 \\
\hline & $(29,8)$ & 0.00873 & $2.37 \mathrm{E}-10$ & $2.10 \mathrm{E}-20$ & $4.27 \mathrm{E}-11$ & 0.007288 & 0.051249 & 0.992712 \\
\hline \multirow[t]{7}{*}{$B_{\text {target }}=0.015$} & $(13,7)$ & 0.009723 & $2.57 \mathrm{E}-10$ & $7.82 \mathrm{E}-21$ & $5.19 \mathrm{E}-11$ & 0.008207 & 0.056938 & 0.991793 \\
\hline & $(15,8)$ & 0.013011 & $7.63 \mathrm{E}-11$ & $3.49 \mathrm{E}-22$ & $1.48 \mathrm{E}-11$ & 0.010926 & 0.075572 & 0.989074 \\
\hline & $(18,8)$ & 0.011059 & $9.50 \mathrm{E}-11$ & $9.79 \mathrm{E}-22$ & $1.81 \mathrm{E}-11$ & 0.009275 & 0.064549 & 0.990725 \\
\hline & $(20,8)$ & 0.013152 & $2.05 \mathrm{E}-10$ & $5.10 \mathrm{E}-21$ & $3.82 \mathrm{E}-11$ & 0.01102 & 0.076364 & 0.98898 \\
\hline & $(23,9)$ & 0.011411 & $2.18 \mathrm{E}-11$ & 4.39E-23 & $4.01 \mathrm{E}-12$ & 0.009544 & 0.066541 & 0.990456 \\
\hline & $(25,9)$ & 0.013026 & $3.94 \mathrm{E}-11$ & $1.58 \mathrm{E}-22$ & $7.18 \mathrm{E}-12$ & 0.01089 & 0.075654 & 0.98911 \\
\hline & $(27,9)$ & 0.014612 & $6.72 \mathrm{E}-11$ & $5.01 \mathrm{E}-22$ & $1.21 \mathrm{E}-11$ & 0.012205 & 0.08453 & 0.987795 \\
\hline
\end{tabular}


Table 2 continued

\begin{tabular}{lllllllll}
\hline & $\left(s^{*}, r^{*}\right)$ & $B_{n}$ & $B_{h d}$ & $B_{h v}$ & $B_{h}$ & $B$ & $D_{G}$ \\
\hline$B_{\text {target }}=0.02$ & $(12,8)$ & 0.014412 & $3.37 \mathrm{E}-11$ & $3.29 \mathrm{E}-23$ & $6.82 \mathrm{E}-12$ & 0.012215 & 0.083413 & 0.987785 \\
& $(14,9)$ & 0.018281 & $1.15 \mathrm{E}-11$ & $2.10 \mathrm{E}-24$ & $2.23 \mathrm{E}-12$ & 0.015388 & 0.104794 & 0.984612 \\
& $(17,9)$ & 0.015253 & $1.47 \mathrm{E}-11$ & $7.00 \mathrm{E}-24$ & $2.80 \mathrm{E}-12$ & 0.012816 & 0.088101 & 0.987184 \\
& $(19,10)$ & 0.017478 & $3.01 \mathrm{E}-12$ & $1.62 \mathrm{E}-25$ & $5.63 \mathrm{E}-13$ & 0.014665 & 0.100393 & 0.985335 \\
& $(21,10)$ & 0.019654 & $6.70 \mathrm{E}-12$ & $9.95 \mathrm{E}-25$ & $1.23 \mathrm{E}-12$ & 0.016454 & 0.112278 & 0.983546 \\
& $(24,10)$ & 0.016722 & $6.62 \mathrm{E}-12$ & $1.60 \mathrm{E}-24$ & $1.21 \mathrm{E}-12$ & 0.013991 & 0.096228 & 0.986009 \\
& $(26,10)$ & 0.018223 & $1.10 \mathrm{E}-11$ & $5.16 \mathrm{E}-24$ & $2.00 \mathrm{E}-12$ & 0.01524 & 0.104474 & 0.98476 \\
\hline
\end{tabular}

Fig. 2 Effect of $\lambda_{n v}$ on a $B_{n}$, b $B_{h d}$, c $B_{h v}, \mathbf{d} B$, e $D_{G}, \mathbf{f}$ CL for different values of $r$

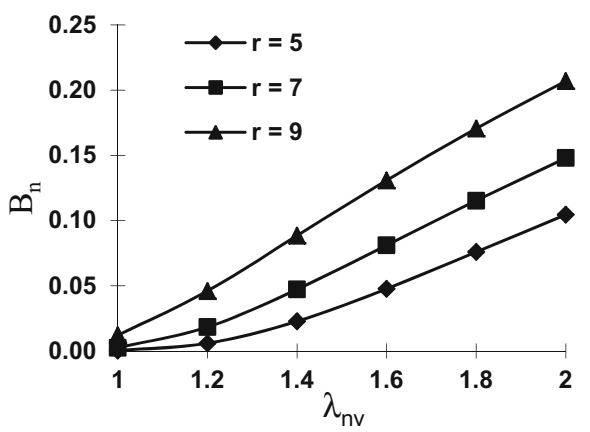

(a)

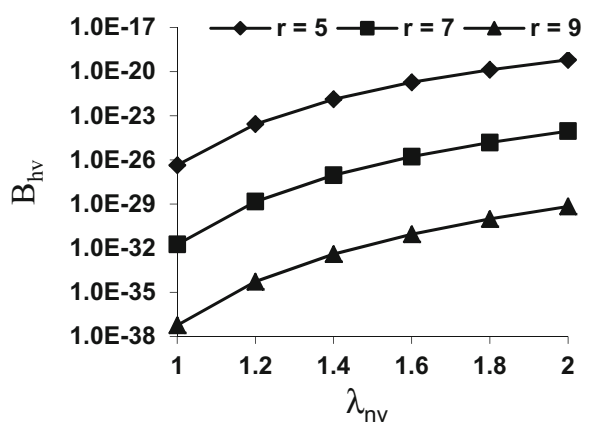

(c)

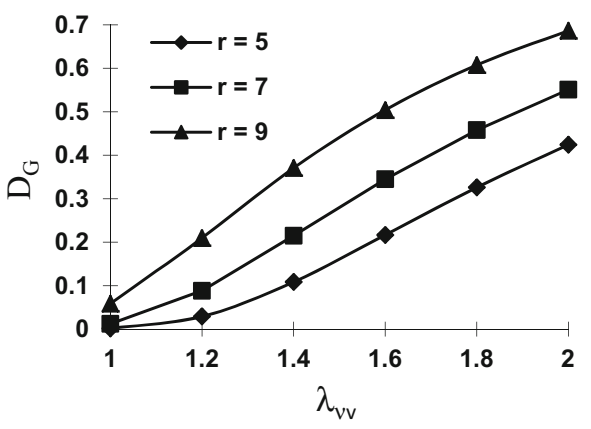

(e)

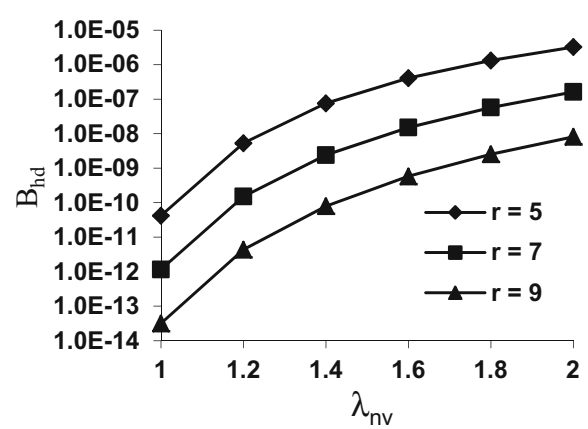

(b)

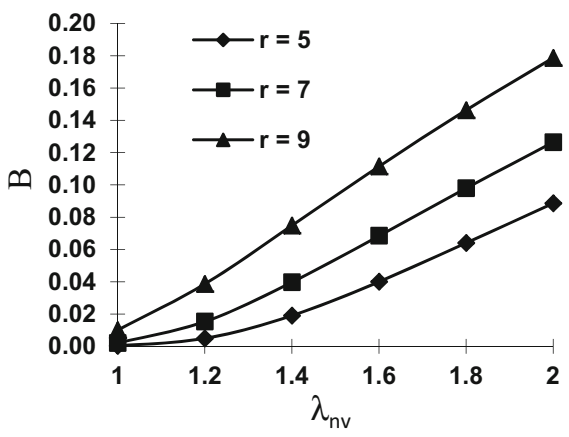

(d)

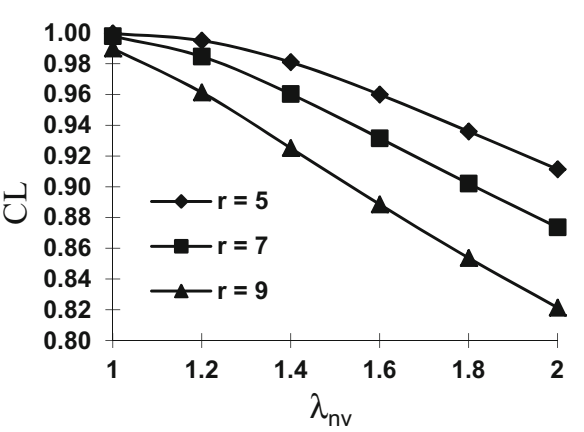

(f) 
Fig. 3 Effect of $\lambda_{n v}$ on a $E[l]$, b $E[D], \mathbf{c} Q_{h v}, \mathbf{d} W_{h v}$ for different values of $r$

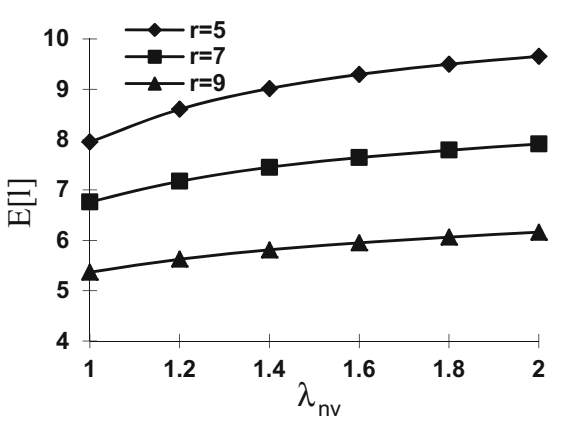

(a)

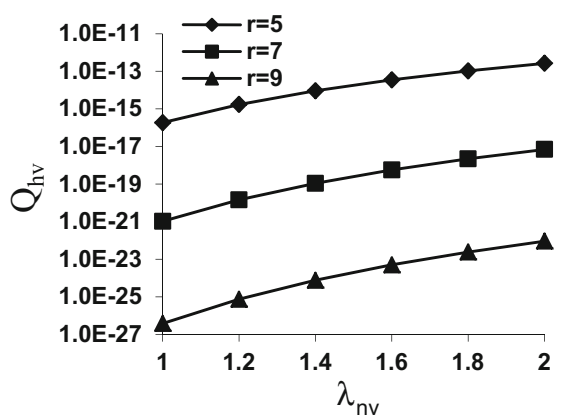

(c)

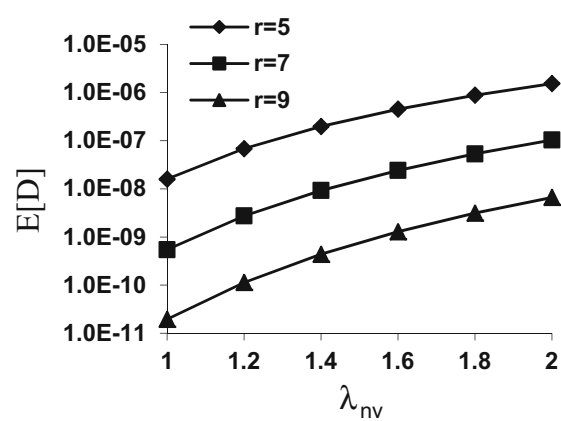

(b)

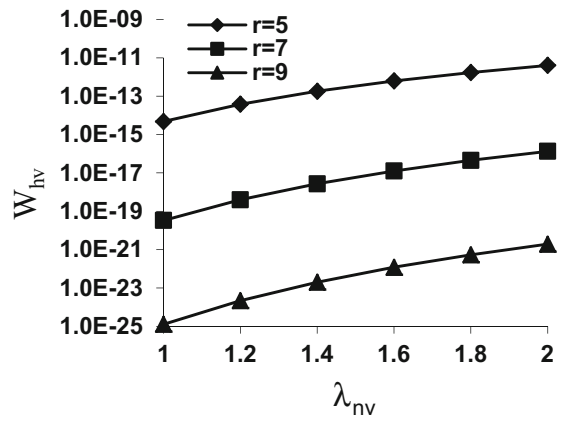

(d) $\lambda_{j, h d}=\frac{\eta\left(1-B_{j, n}\right)}{\mu+\eta D_{j, h d}} \lambda_{j, n d} \quad$ and $\quad \lambda_{j, h v}=\frac{\eta\left(1-B_{j, n}\right)}{\mu+\eta D_{j, h v}} \lambda_{j, n v}$

\section{Handoff Algorithm}

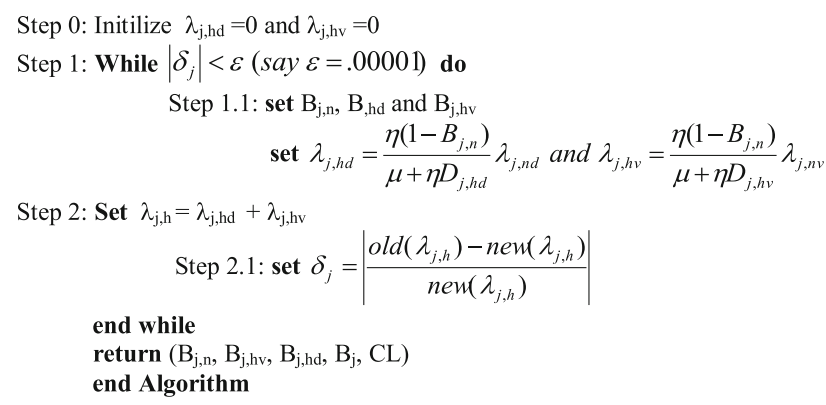

\section{Sensitivity analysis}

In this section, the sensitivity analysis is carried out to examine the analytical results. Various performance indices for the proposed scheme are summarized in Tables 1,2 and Figs. 2, 3, 4. For different values of TC, Table 1 provides the optimal number of channels (unreserved channels and reserved channels) to be allocated in each cell using optimal allocation algorithm by taking $B_{\text {target }}=1 \%$.
The corresponding performance indices like blocking probability of new calls $\left(B_{n}\right)$, blocking probability of handoff data calls $\left(B_{h d}\right)$, blocking probability of handoff voice calls $\left(B_{h v}\right)$, overall blocking probability of handoff calls $\left(B_{h}\right)$, overall blocking probability of calls $(B)$, dropping probability of handoff guaranteed calls $\left(D_{G}\right)$ and $\mathrm{CL}$ in every cell, are also tabulated. For different values of $B_{\text {target, }}$ Table 2 displays the results for various performance indices for TC $=200$. For these results, a cluster of 7 cells is taken, i.e., $K=7$ and the buffer size is taken as $N=5$.

Figure $2 \mathrm{a}-\mathrm{f}$ shows the effect of arrival rate of new voice calls $\left(\lambda_{n v}\right)$ on $B_{n}, B_{h d}, B_{h v}, B$, and CL for different values of reserve channels $(r)$. For this we choose the default parameters as $c=15, N=5, \lambda_{\text {nd }}=1, \beta=0.3, v=0.2$, $\mu=0.5$, and $\eta=0.1$. Figure $2 \mathrm{a}, \mathrm{d}$, e depict that $B_{n}, B$ and $D_{G}$ first increases slowly then sharply with respect of $\lambda_{n v}$. $B_{n}, B$, and $D_{G}$ also increase as $\mathrm{r}$ increases. In Fig. $2 \mathrm{a}, \mathrm{b} B_{h d}$ and $B_{h v}$ increase sharply with respect to $\lambda_{n \mathrm{v}}$ whereas $B_{h d}$ and $B_{h v}$ decrease on increasing r. Figure $2 \mathrm{f}$ shows that $\mathrm{CL}$ decreases sharply with $\lambda_{n v}$ and $r$ both.

Figures $3 a-d$ and $4 a-d$ shows the effect of arrival rate of new voice calls and new data calls $\left(\lambda_{n v}\right.$ and $\left.\lambda_{n d}\right)$ on expected number of busy channels $(E[l])$, average queue length of handoff voice calls $\left(Q_{h v}\right)$ and waiting time of handoff voice calls $\left(W_{h v}\right)$, respectively, for different values of $r$. Figure $3 \mathrm{a}$ depicts that $E[l]$ increases slowly as we 
Fig. 4 Effect of $\lambda_{n d}$ on a $E[l]$, b $E[D], \mathbf{c} Q_{h v}, \mathbf{d} W_{h v}$ for different values of $r$

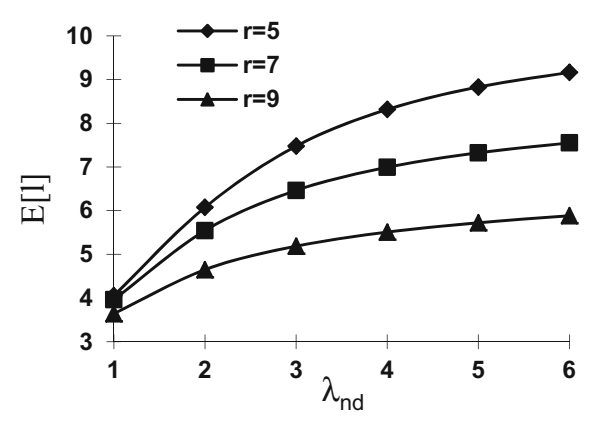

(a)

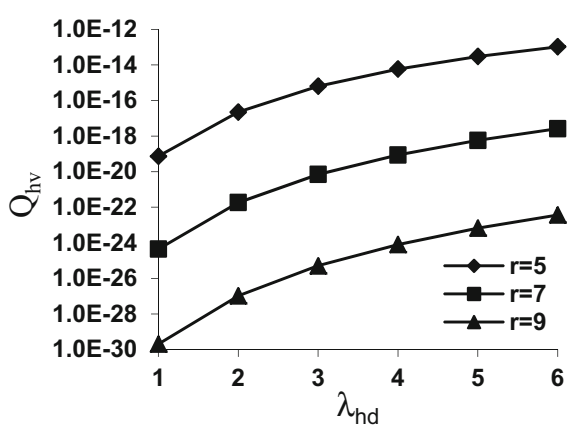

(c)

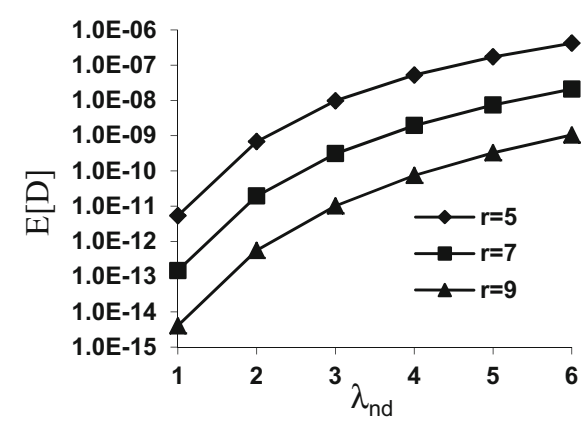

(b)

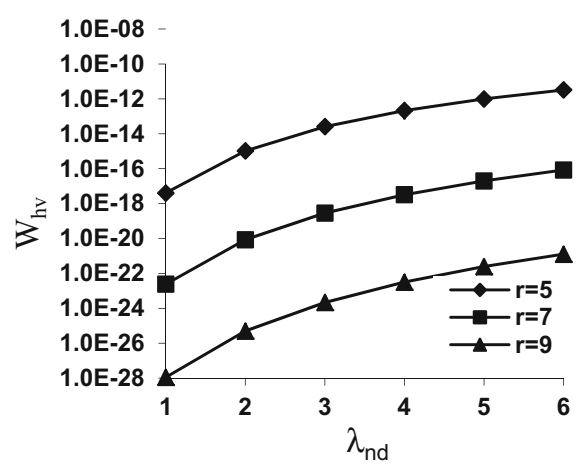

(d) increase $\lambda_{n v}$ whereas in Fig. 4a $E[l]$ increases first sharply then gradually as $\lambda_{n d}$ increases.

In Figs. $3 \mathrm{~b}$ and $4 \mathrm{~b}$, it is noticed that $E[D]$ increases sharply on increasing $\lambda_{n v}$ and $\lambda_{n d}$, respectively, whereas $E[D]$ decreases gradually on increasing $\mathrm{r}$ which is quite obvious because as the number of reserved channels increases, less degradation is achieved in handoff voice calls. Figures $3 \mathrm{c}, \mathrm{d}$ and $4 \mathrm{c}, \mathrm{d}$ shows that $Q_{h v}$ and $W_{h v}$ increase sharply as $\lambda_{n v}$ and $\lambda_{n d}$ increase whereas there is a sharp decrement in $Q_{h v}$ and $W_{h v}$ as $r$ increases. The trend of $Q_{h v}$ is quite at par as we expect.

Overall, we conclude that all performance measure except CL increase as arrival rate of new data calls and new voice calls increase which is the same as we expect and realize in real time system. The indices $B_{n}, B, D_{G}$ and $\mathrm{CL}$ decrease as $\mathrm{r}$ increases whereas $B_{h d}, B_{h v}, E[l], E[D]$, $Q_{h v}$ and $W_{h v}$ reveals the decreasing trend on increasing r.

\section{Conclusion}

The rapid growth in demand for mobile communication has led to intense research and development efforts towards a new generation of cellular systems. The new system must be able to provide GoS, support a wide range of services and improving the system capacity. Resource allocation and admission control are the two major issues which are faced by today's wireless/cellular industry. To control the admission of the incoming calls, the proposed priority channel assignment scheme may provide insights to the system designers and decision makers to utilize the bandwidth optimally. The optimal allocation algorithm suggested may be utilized to develop a controller which can optimally allocate the ordinary channels and guard channels in each cell of the cluster in cellular network. We have developed an iterative algorithm to computes the arrival rate of handoff calls in an efficient manner. The sensitivity analysis presented, exhibits the validity of the proposed algorithms.

Open Access This article is distributed under the terms of the Creative Commons Attribution 4.0 International License (http://crea tivecommons.org/licenses/by/4.0/), which permits unrestricted use, distribution, and reproduction in any medium, provided you give appropriate credit to the original author(s) and the source, provide a link to the Creative Commons license, and indicate if changes were made.

\section{References}

Artalejo JR, Pla V (2009) On the impact of customer balking, impatience and retrials in telecommunication systems. Comput Math Appl 57(2):217-229

Choi YJ, Kim J, Bahk S (2006) QoS-aware selective feedback and optimal channel allocation in multiple shared channel environments. IEEE Trans Wirel Commun 5(11):3278-3286 
Chowdhury KR, Nandiraju N, Chanda P, Agrawal DP, Zeng Q (2009) Channel allocation and medium access control for wireless sensor networks. Ad Hoc Netw 7(2):307-321

Galtier J (2001) Geographical reservation for guaranteed handover and routing in low earth orbit constellations. Telecommun Syst 18(1-2):101-121

Gross D, Harris MC (2003) Basic concepts of queueing theory. Wiley, Singapore

Haghighi AM, Mishev DP (2006) A parallel priority queueing system with finite buffers. J Parallel Distrib Comput 66:379-392

Hashemin SS, Ghomi SMTF (2012) Constrained consumable resource allocation in alternative stochastic networks via multiobjective decision making. J Ind Eng Int 8(18):1-9

Huang L, Kumar S, Kuo CCJ (2004) Adaptive resource allocation for multimedia QoS management in wireless networks. IEEE Trans Veh Technol 53(2):547-558

Islam MM, Murshed M (2007) Parametric mobility support dynamic resource reservation and call admission control scheme for cellular multimedia communications. Comput Commun 30(2):233-248

Jain M (2003) Prioritized handover request in cellular radio system with subrating for intrgrated voice/data traffic. IETE J Res 49(6):378-398

Jain M (2005) Channel allocation policy in cellular radio network. Appl Math Model 29(1):65-83

Jain M, Mittal R (2011) Performance analysis in a double layer cellular network with new call bounding scheme and directed retry. CSI J Comput Sci Eng 9(2):1-10

Jain M, Mittal R (2015) Call admission control for soft handoff coverage in CDMA cellular system. Int $\mathrm{J}$ Wirel Inf Netw 22:53-66

Jain M, Rakhee (2001) Queueing analysis for PCS with integrated traffic and subrating channel assignment scheme. J Comput Sci Inf 31(2):1-8

Jain M, Rakhee (2003) Priority based channel assignment scheme for PCS with integrated traffic. J Comput Sci Inf 33(1):8-18

Jain M, Priya K, Rakhee (2003a) Optimal channel allocation in cellular systems. J Inf Commun Technol 2(2):41-64

Jain M, Sharma GC, Saraswat VK (2003b) Channel assignment schemes for PCS with cutoff priority and subrating. Int J Inf Comput Sci 6(2):46-56

Jain M, Sharma GC, Mittal R (2008) Transient analysis of channel allocation in cellular radio network with balking and reneging. Comput Soc India 38(4):11-19

Jain M, Sharma GC, Mittal R (2013) Performance analysis of prioritized call admission control schemes for integrated traffic in wireless network. Int $\mathbf{J}$ Electron Commun Comput Eng 4(1):283-291

Jain M, Sharma GC, Mittal R (2014a) Call admission control and resource allocation of wireless networks. Int $\mathrm{J}$ Wirel Mob Comput 7(6):577-590

Jain M, Sharma GC, Mittal R (2014b) Queueing analysis and channel assignment scheme for cellular radio system with GPRS services. Int J Math Oper Res 6(6):704-731
Jain M, Sharma GC, Mittal R (2015) ANN model for multi channel infinite buffer queue under N-policy. Int J Oper Res 24(1):59-82

Jayarin PJ, Ravi T (2012) Optimal channel allocation mechanism to improve the QoS in wireless networks. Int J Comput Appl 45(20):30-34

Kia R, Shirazi H, Javadian N, Tavakkoli-Moghaddam R (2013) A multi-objective model for designing a group layout of a dynamic cellular manufacturing system. J Ind Eng Int 9(8):1-14

Krishna PV, Iyengar NCSN (2008) Optimal channel allocation algorithm with efficient channel reservation for cellular networks. Int J Commun Netw Distrib Syst 1(1):33-51

Kumar A, Bhushan A, Kumar M (2012) A study on minimization of 2G/3G handover failure. Int J Adv Res Comput Sci Softw Eng 2(4):4-7

Lin P (2003) Channel allocation for GPRS with buffering mechanisms. Wirel Netw 9:431-441

Lin YB, Anthony R, Harasty DJ (1996) The sub-rate channel assignment strategy for PCS handoffs. IEEE Trans Veh Technol 45(1):122-130

Mittal R, Jain M (2015) Maximum entropy analysis of $M^{x} / G / 1$ retrial queue with $k$-phases of heterogeneous service and impatient calls under different vacation policies. Am J Math Manag Sci 34(2):117-146

Ning Z, Song Q, Guo L, Chen Z, Jamalipour A (2015) Integration of scheduling and network coding multi rate wireless mesh networks optimization models and algorithms. Adhoc Netw. doi:10.1016/j.adhoc.2015.08.013

Rashad S, Kantardzic M (2006) User mobility oriented predictive call admission control and resource reservation for next generation mobile networks. J Parallel Distrib Comput 66(7):971-988

Samanta RK, Bhattacharjee P, Sanyal G (2010) Performance analysis of cellular wireless network by queueing priority handoff calls. Int J Electr Electron Eng 3(8):472-477

Sharma G, Purohit GN (2011) Queueing modeling of handoff calls with subrating in wireless cellular netwrok. Appl Math Sci 5(21): 1017-1024

Shet NSV, Chandrasekaran K, Shet KC (2010) Implementation of handoff through wireless access point techniques. J Telecommun 2(2):143-146

Tang S, Li W (2007) Performance analysis of a channel allocation scheme for multi-service mobile cellular networks. Int $\mathrm{J}$ Commun Syst 20:177-205

Wu X, He M, Wang F, Zheng J, Regentova E, Hao G (2009) Performance analysis of sub-rating for handoff calls in HCN. Int J Commun Netw Syst Sci 2(1):21-29

Wu X, Jaekel A, Bari A (2011) Optimal channel allocation for dynamic power control in cellular networks. Int J Comput Netw Commun 3(2):83-93

Yaghoubi S, Noori S, Mazdeh MM (2013) A heuristic method for consumable resource allocation in multi-class dynamic PERT networks. J Ind Eng Int 9(17):1-12 